\title{
EJNSO
}

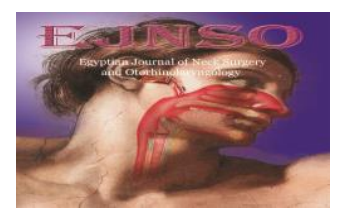

\section{Effect of sinonasal surgery on middle ear pressure}

\author{
Asmaa Eyon Abd El-bary ${ }^{1}$, MsC, Mohamed Mostafa Osman ${ }^{2}$, MD \\ Amira Mohammed A. Eloseily ${ }^{3}$, MD, Mohamed Abdel-Azez Mohamed ${ }^{2}$, MD \\ 1. Otorhinolaryngology Department El-Eman General Hospital - Assiut. \\ 2. Otorhinolaryngology, Faculty of Medicine- Assiut University. \\ 3. Audiology, Faculty of Medicine-Assuit University.
}

\begin{abstract}
Introduction: Eustachian tube is often involved in the pathological processes of the nasal, paranasal, and nasopharynx cavities; therefore, nasal obstruction can alter Eustachian tube function (ETF). The pathogenesis of otitis media has been related to the presence of previous or concurrent nasal diseases.
\end{abstract}

Objective: to study whether there are changes in middle ear pressure after sinonasal surgery.

Materials and methods: 59 patients who had different nasal pathologies were subjected to History taking, Clinical examination and Tympanometry. ETF tests in the form of valsalva, Toynbee maneuvers and tympanometry had been performed the day before the operation and after 6 weeks. The postoperative middle ear pressure levels were determined using tympanometry. The middle ear pressure values obtained before and after surgery were compared to determine if there is a statistically significant result.

Results: There were a significant improvement of nasal obstruction, ear fullness and tinnitus after surgery. The relation between the middle ear pressure preoperatively and at 6 weeks after removal of nasal packs showed a significant improvement in middle ear pressure $(\mathrm{P}<0.05)$ in both ears .

Conclusions: Sino-nasal surgery has a favorable effect on the middle ear pressure and Eustachian tube function.

Keywords: Eustachian tube, sinonasal surgery, middle ear pressure.

\section{Introduction}

The eustachian tube is the only tube connecting the middle ear and the nasopharynx (atmospheric space) and has long been recognized as the main organ ventilating the middle ear. Normally, the bony portion, part of the isthmus, and the pharyngeal orifice of the tube are always open, but the cartilaginous portion is closed when at rest. Thus, the middle ear is a closed space which is shut off from atmospheric space ${ }^{1}$.

Tympanometry and Eustachian tube function (ETF) tests (Valsalva and Toynbee maneuvers) can evaluate the ETF; thus, they have been used widely in clinical and basic research investigations. Patients with tubal dysfunction often complain of a sensation of fullness in ear, which is a result of the functional impairment of 
the Eustachian tube that results from a ventilatory disturbance. However, despite the sensation of ear fullness, most patients show normal middle ear pressure as measured by tympanometry 2 .

The tube is often involved in the pathological processes of the nasal, paranasal, and rhinopharynx cavities; therefore, nasal obstruction can alter ETF ${ }^{3}$. The pathogenesis of otitis media has been related to the presence of previous or concurrent nasal diseases, such as upper respiratory tract viral infection and allergy. In particular, allergic rhinitis is known to be one of the chief causes of chronic nasal obstruction ${ }^{4-8}$.

It has been reported that patients with even a slight septal deviation have a tubal dysfunction with a consequent middle ear pressure depression ${ }^{9}$.

\section{Patients and Methods:}

\section{Patients:}

The study included 59 patients who had different nasal pathologies (deviated nasal septum, chronic hypertrophic rhinitis, bilateral nasal polyposis, chronic sinusitis).

The study had been carried out in outpatient clinic and department of otolaryngology at Assiut university hospital.

\section{Inclusion criteria:}

Patients were subjected to different nasal surgeries for treating their pathologies (different age groups).

\section{Exclusion criteria:}

Patients with tympanic membrane perforation, acute rhinitis, history of recurrent middle ear infection and previous nasal surgery.

This study was approved by the Institutional Ethics and Research Committee of the Faculty of Medicine, Assiut University, Assiut, Egypt. The whole study was explained to the patients and a written consent was taken. They were completely free to be included in the study or not.

\section{Methods:}

Each patient was subjected to history taking, Clinical examination and Tympanometry.

Eustachian tube function tests in the form of valsalva, Toynbee maneuvers and tympanometry had been performed the day before the operation and after a 6-week period that was necessary for wound healing, the patients were examined; again, ear cerumen, if present, was removed. The postoperative middle ear pressure levels were determined using tympanometry. The middle ear pressure values obtained before and after surgery were compared to determine if there was a statistically significant result.

\section{Valsalva maneuver}

To evaluate the ability to inflate the middle ear actively, patients were asked to pinch the nose and inflate the cheeks through forced expiration with the mouth closed until a sensation of fullness was achieved in the ears. Patients were then instructed to release the nose and abstain from further swallowing or mandibular movement and an experimental tympanogram was obtained in each ear.

\section{Toynbee maneuver}

To evaluate the capacity to equalize the middle ear pressure and the nasopharyngeal pressure, patients were asked to swallow while pinching the nose. Patients were then instructed to release the nose and refrain from further swallowing and mandibular movement, and an experimental tympanogram was obtained from each ear. Tympanometric peak shift (generally negative) between baseline and experimental tympanogram less than $10 \mathrm{daPa}$ indicated poor ETF, whereas a tympanometric peak pressure shift of greater than $10 \mathrm{daPa}$ indicated a good ETF. 


\section{Tympanometry}

The tympanograms were classified in the standard manner according to Jerger ${ }^{10}$. A tympanogram with middle ear pressure peak between +50 and $-100 \mathrm{daPa}$ was classified as type A. Tympanogram with middle ear pressure peak of $-100 \mathrm{daPa}$ or more negative was classified as type C. A tympanogram with a flattened peak of less than $0.3 \mathrm{ml}$ admittance was classified as type B.

*Equipment used in Toynbee maneuver and tympanometry: Interacoustics ATH 235 tympanometer.

\section{Statistical analysis:}

The collected data were revised, organized, tabulated and statistically analyzed using statistical package for social sciences (SPSS) version 23.0 for windows. Data are presented as the Mean \pm standard deviation (SD), frequency, and percentage. Categorical variables were compared using the chisquare $(\chi 2)$ and Fisher's exact tests (if required). Mann-Whitney $U$ and Wilcoxon sign tests for nonparametric data. The level of significance was accepted if the $P$ value $<0.05$

\section{Results:}

The study was carried out on 59 patients who were complaining of different nasal and sino-nasal pathology that required surgery.

All patients were operated on according to the cause of the pathology. They were 37 males $(62.7 \%)$ and 22 females $(37.3 \%)$. The age of the patients ranged from 10 to 60 years, mean age (30.44 \pm 11.34$)$ years.

All patients were operated on according to the cause of the sinonasal pathology as shown in [Table 1]

Relation of patients' complaints before and after nasal surgery:

There is significant improvement of sensation of nasal obstruction, ear fullness and tinnitus after surgery as shown in (figure1).
Table (1) Type of sinonasal surgery among studied patients, $\mathrm{N}=59$

\begin{tabular}{|l|c|l|}
\hline Type of surgery & N. & \% \\
\hline FESS inferior & 19 & 32.2 \\
\hline $\begin{array}{l}\text { Bilateral } \\
\text { turbinectomy resection of }\end{array}$ & 10 & 25.4 \\
\hline $\begin{array}{l}\text { Submucous } \\
\text { nasal septum }\end{array}$ & 8 & 13.6 \\
\hline Excision of nasal polyps & 7 & 11.9 \\
\hline $\begin{array}{l}\text { Excision of antrochoanal } \\
\text { polyp }\end{array}$ &
\end{tabular}

The relation between the middle ear pressure preoperatively and postoperatively after removal of nasal packs:

The relation between the middle ear pressure preoperatively and at 6 weeks after removal of nasal packs is shown in (Table 2), with a significant improvement in middle ear pressure $(\mathrm{P}<$ 0.05 ) in both ears.

Preoperatively, the values of middle ear pressure ranged from -50 to -25 $\mathrm{daPa}$, mean $-43 \mathrm{daPa}$ in $\mathrm{RT}$ ear with a significant improvement post operatively ranged from -50 to-36 daPa , mean $-36 \mathrm{daPa}(\mathrm{P}<0.001)$. Also, the values of middle ear pressure ranged from -53 to- $28 \mathrm{daPa}$, mean $-38.5 \mathrm{daPa}$ in LT ear with a significant improvement post operatively ranged from -50 to $-4 \mathrm{daPa}$, mean $-28.5 \mathrm{daPa}(\mathrm{P}$ $<0.001)$.

Table 2 Tympanometry pressure results before and after sinonasal surgery. Total $\mathbf{N}=59$.

\begin{tabular}{|c|c|c|c|}
\hline & $\begin{array}{c}\text { Before } \\
\text { surgery }\end{array}$ & $\begin{array}{c}\text { After } \\
\text { surgery }\end{array}$ & P-value \\
\hline $\begin{array}{c}\text { Rt ear } \\
\text { Median } \\
\text { (IQR) }\end{array}$ & $\begin{array}{c}-43(-50, \\
-25)\end{array}$ & $\begin{array}{c}-36(-50, \\
-36)\end{array}$ & $\mathbf{0 . 0 0 7} \mathbf{S}^{*}$ \\
\hline $\begin{array}{c}\text { Lt ear } \\
\text { Median } \\
\text { (IQR) }\end{array}$ & $-38.5(-$ & $-28.5(-$ & $\mathbf{0 . 0 4 9} \mathbf{S}^{*}$ \\
\hline
\end{tabular}

*Wilcoxon test was used: * S: statistically significant difference, $\mathrm{P}<0.05$. 
The relation between the tympanometric type preoperatively and at 6 weeks after removal of nasal packs:

There is a significant improvement in tympanometric type from $\mathrm{C}$ to $\mathrm{A}$ ( $\mathrm{P}$ $<0.05$ ) in both ears as shown in (Table 3).

\section{Compliance results before and after} sinonasal surgery:

There is significant improvement of compliance values in both ears after sinonasal surgery and nasal packs removal.

Table 4: Compliance results before and after sinonasal surgery; total $N_{.}=59$.

\begin{tabular}{|c|c|c|c|}
\hline & $\begin{array}{c}\text { Before } \\
\text { surgery }\end{array}$ & $\begin{array}{c}\text { After } \\
\text { surgery }\end{array}$ & P-value \\
\hline Rt ear & $0.60(0.4$, & $0.67(0.5$, & $\mathbf{0 . 0 2 6 ~ S} *$ \\
Median & $0.84)$ & $1.6)$ & \\
$(I Q R)$ & & & \\
\hline Lt ear & $0.66(0.5$, & 0.71 & $<\mathbf{0 . 0 0 1}$ \\
Median & $0.71)$ & $(0.49$, & HS* \\
(IQR) & & $1.42)$ & \\
\hline
\end{tabular}

*Wilcoxon test was used: * S: statistically significant difference, $\mathrm{P}<0.05$. HS: High statistically significant difference, $\mathrm{P}<0.001$.

\section{Comparison between acoustic} reflexes before and after sinonasal surgery: There is no significant change in both ears.

The relation between the ETF preoperatively and 6 weeks after removal of nasal packs:

ETF evaluated by valsalva and toynbee maneuvers. There is a significant improvement in ETF after the sinonasal surgery.

\section{Discussion :}

Evaluation of Eustachian tube functions in ears with intact tympanic membrane can be done using tympanometry, sonotubometry, manometry, inflation deflation tests, and the Valsalva and Toynbee maneuvers ${ }^{11-}$
13. In case Tymanometric Pressure changes by more than $10 \mathrm{daPa}$ in the positive direction with the Valsalva maneuver and changes by more than 10 $\mathrm{daPa}$ in the negative direction with the Toynbee maneuver, ET functions can be said to be good ${ }^{10,14}$.

Nose, paranasal sinuses, and nasopharyngeal diseases can disrupt the functions of the ET 15-17. Three mechanisms were postulated for Eustachian tube dysfunction after nasal obstruction: first, airflow turbulence may lead to deposition of microorganisms and air pollutants in the region of Eustachian tube opening, resulting in tubal epithelium or peritubal inflammation and mechanical obstruction. Second, tubal mucous viscosity and surface tension may be increased by the drying effects of altered air currents, leading to increased tubal opening pressure. The third postulated mechanism is that the postnasal mechanical receptors' end on autonomic nerve supply to the Eustachian tube may be stimulated by altered air currents, leading to a reflex alteration in ETF ${ }^{18}$.

Among the studies that have investigated the effects of nasal obstruction on ET functions, the clinical study by Salvinelli et al., $2005^{14}$ and the experimental study by Eyigör et al., $2013^{18}$ showed that it was clear that nasal obstruction had an effect on middle ear pressure and ETF .

In nasal obstruction, the difference in pressure between the middle ear and nasopharynx is not changed with passive function but is changed with active function ${ }^{19}$. 


\section{Complaints}

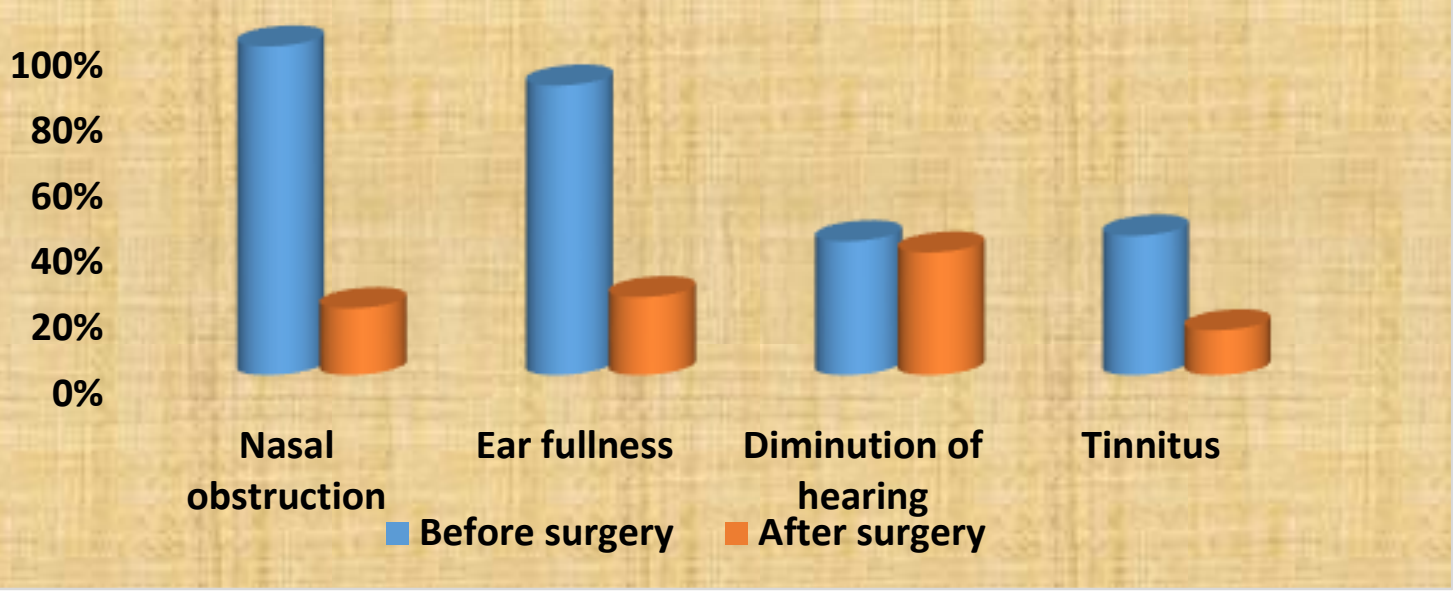

Figure (1): Relation of patients' complaints before and after nasal surgery

Table 3: Comparison between tympanometeric types before and after sinonasal surgery. Total $\mathbf{N}=59$.

\begin{tabular}{|c|c|c|c|c|c|c|}
\hline \multicolumn{2}{|c|}{} & \multicolumn{2}{|c|}{ Before surgery } & \multicolumn{2}{c|}{ After surgery } & \multirow{2}{*}{ P-value } \\
\cline { 3 - 6 } \multicolumn{2}{c|}{} & $\mathbf{N}$ & $\mathbf{\%}$ & $\mathbf{N}$ & $\mathbf{\%}$ & \\
\hline \multirow{3}{*}{$\begin{array}{c}\text { Rt } \\
\text { ear }\end{array}$} & Type A & 41 & 69.5 & 53 & 89.8 & \multirow{3}{*}{$0.042 \mathrm{~S}^{*}$} \\
\cline { 2 - 6 } & Type B & 5 & 8.5 & 4 & 6.8 & \\
\cline { 2 - 6 } & Type C & 13 & 22.0 & 2 & 3.4 & \\
\hline \multirow{3}{*}{$\begin{array}{c}\text { Lt } \\
\text { ear }\end{array}$} & Type A & 39 & 66.1 & 52 & 88.4 & \multirow{3}{*}{$0.048 \mathrm{~S}^{*}$} \\
\cline { 2 - 6 } & Type B & 3 & 5.1 & 4 & 6.8 & \\
\cline { 2 - 6 } & Type C & 17 & 28.8 & 3 & 5.8 & \\
\hline
\end{tabular}

* Fisher's exact test was used test was used: * S: statistically significant difference, $\mathrm{P}<0.05$.

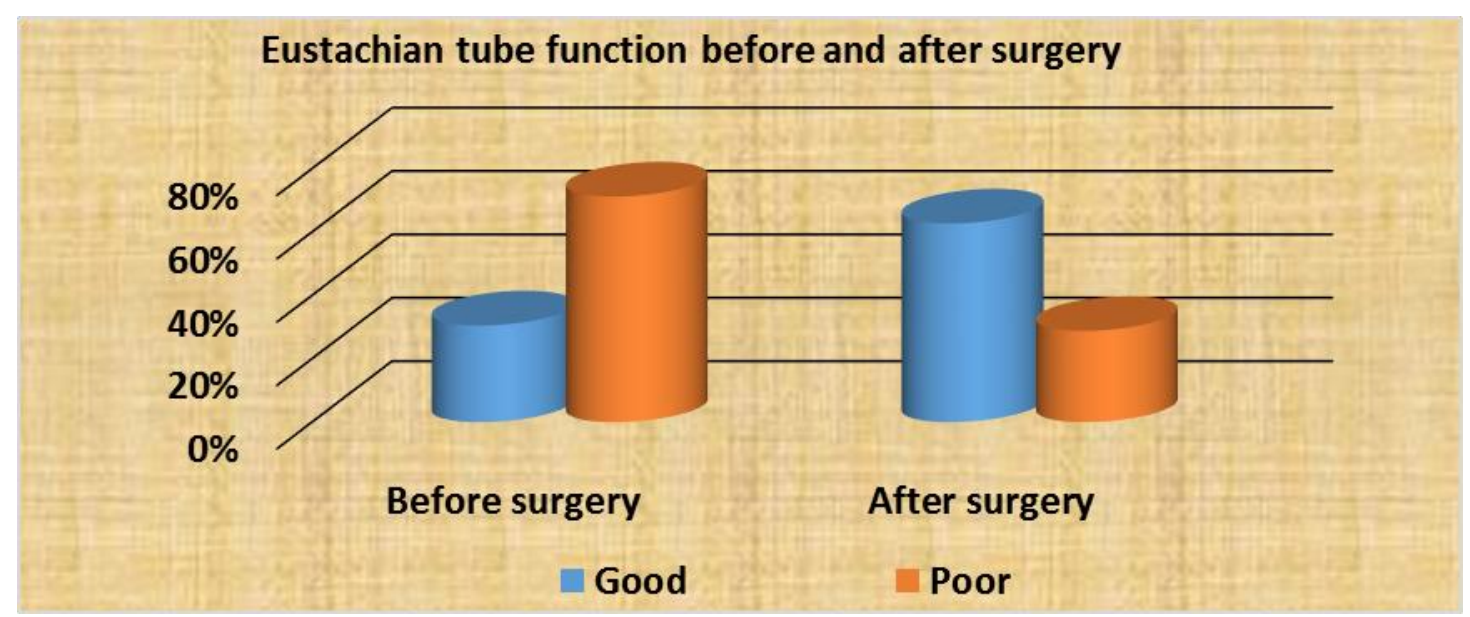

Figure (2): Comparison between Eustachian tube function tests before and after sinonasal surgery. 
The findings of our study demonstrated that in patients with different nasal and sinonasal pathologies that required surgery, there were significant changes in middle ear pressure values postoperative in both ears.

These results are similar to those reported by Low and Williatt ${ }^{20}$, who evaluated patencies of the nasal passages (measured with a peak nasal inspiratory flowmeter) and middle ear pressure (MEP) measured with a tympanometer of 40 patients prior to surgery and 6-10 months post-operatively .

However, these results differ from those of Salvinelli et al., $2005{ }^{14}$ who found that there were no significant differences between tympanometric values in the preoperative and postoperative periods up to the 90th day .

Also, the results of our study showed that there is a significant effect of sinonasal surgery on the type of tympanometry, where there was improvement of tympanometric type A up to $20 \%$ and decrease in type $\mathrm{C}$ by the same value in both ears .

These results are similar to those reported by Low and Williatt ${ }^{20}$, Nurdat et al., ${ }^{21}$ who proved that there was a significant increase in the number of (type A) cases with reduction of (type B and type C) cases post operatively in patients with nasal polyps. This concluded that operations for correction of nasal obstruction will improve the Eustachian tube functions and so, will statistically improve the increase in the tympanometric results towards the normal side after one month of the operation.

When we assessed the changes in ETF postoperatively, there was a significant improvement; this was similar to the results of Salvinelli et al. 14.

Awad et al., $2014{ }^{22}$ reported similar results as regards the type of tympanometry, tympanometric values and Eustachian tube function. They reported that, postoperative results of ETF tests were significantly better than preoperative results. Significant improvement in tympanometeric values was also found marked improvement of ear fullness was detected 6 weeks after surgery .

Our results are somewhat different from other studies ${ }^{23-24}$. Maier and Krebs ${ }^{23}$ concluded that dysfunction of the Eustachian tube frequently occurs in patients with deviation of the nasal septum and the conchae. Septoplasty and conchotomy worsen tubal function during the early postoperative period, lasting for at least one week. In a later period, improvement of tubal function may occur but in many patients no effects of nasal surgery on Eustachian tube can be measured. Thus, septoplasty before tympanoplasty cannot be generally recommended in all patients with septal deviation. The nasal septal suture technique is less likely to affect acoustic tympanometry, arterial oxygen, and carbon dioxide values ${ }^{25}$.

Sahin et al. $2014{ }^{24}$ reported that septoplasty, which was objectively shown to establish nasal patency, does not cause any changes in middle ear pressure or Eustachian tube functions.

The packing used in septoplasty causes the Eustachian dysfunction ${ }^{3}$. The use of packing after septoplasty can cause tubal dysfunction because of the edema due to surgery or direct obstruction of the Eustachian tube, but it lasts for a brief time ${ }^{26}$. The general anesthesia also affects the middle ear pressure, but this effect does not last after ${ }^{17}$.

Our findings demonstrated that, there were significant changes in the tympanometric types, compliance values, Eustachian tube function but no significant changes in acoustic reflexes before and after sino-nasal surgery. The 
compliance value was significantly improved postoperatively after removal of nasal packing.

The influence of nasal septal deviation and its surgical correction on the opening pressure of the Eustachian tube was studied by Deron et al ${ }^{27}$ who reported that, on the basis of early and late post-operative measurements, it was stated that surgical correction of a nasal septal deviation in order to improve the tubal opening pressure is justified, both on the deviated side and on the nondeviated side. Late post-operative results confirmed this finding .

In our study, the postoperative test was done 6 weeks later; a significant improvement was found in the middle ear pressure at the side of the pathology.

From the above results, it is clear that there are many sino-nasal pathologies which may cause Eustachian tube dysfunction and can lead to middle ear hypoventilation, and that sino-nasal surgery improves tubal function and middle ear ventilation at least 6 weeks after the surgical procedure.

Our data support the results of Salvinelli et al ${ }^{14}$, who suggested that tympanoplasty and nasal surgery should not be performed at the same time and that middle ear surgery should be carried out at least 3 months after nasal surgery when the anatomy and physiology of nasal, pharyngeal, and tubal mucosa have returned to normal because the Eustachian tube dysfunction and the consequent hypoventilation of middle ear are among the most frequent causes of failure of middle ear surgery. Moreover, failures in middle ear surgery are more likely to occur in patients with nasal function impairment.

\section{Conclusion:}

Surgical correction of sinonasal pathology has a favorable effect on patients' complaints and significantly improves middle ear pressure and
Eustachian tube function.

\section{Conflicts of interest}

The authors declared no potential conflicts of interest with respect to the research, authorship and/or publication of this article.

\section{References:}

1. Takahashi H. Middle-ear physiology: ventilation and pressure regulation. InThe Middle Ear 2001 (pp. 1-19). Springer, Tokyo.

2. Iwano $T$, Kinoshita $T$, Hamada $E$, Ushiro K, Yamashita T, Kumazawa T. Sensation of ear fullness caused by eustachian tube dysfunctions. Auris Nasus Larynx. 1991 Jan 1;18(4):343-349.

3. González FG, Garabal JG, Torres TL, Guerrero DG, López DA. The Toynbee's phenomenon effect on the middle ear during nasal tamponade. InAnales otorrinolaringologicos iberoamericanos 1997 (Vol. 24, No. 4, pp. 393-400).

4. Fiellau-Nikolajsen M, Højslet PE, Felding JU. Adenoidectomy for eustachian tube dysfunction: longterm results from a randomized controlled trial. Acta OtoLaryngologica. 1982 Jan 1;93(sup386):129-31.

5. Ruggeri C, Barberio G, Pajno GB, Putorti A, Morabito L, Pollicino A, Galletti F, Muscianisi F, Galletti B, Messina G. An assessment of middle ear involvement in children with allergic rhinitis: a comparison with chronic hypertrophic adenoiditis. La Pediatria medica e chirurgica: Medical and surgical pediatrics. 1990;12(5):491-3.

6. Knight LC, Eccles R, Morris S. Seasonal allergic rhinitis and its effects on eustachian tube function and middle ear pressure. Clinical 
Otolaryngology \& Allied Sciences. 1992 Aug;17(4):308-12.

7. Horak F. Impact and modulation of nasal obstruction. Allergy. 2002 Dec 1;57:25-8.

8. Sims EJ, Wilson AM, White PS, Gardiner Q, Lipworth BJ. Shortterm repeatability and correlates of laboratory measures of nasal function in patients with seasonal allergic rhinitis. Rhinology. 2002 Jun;40(2):66-8.

9. Low WK, Willatt DJ. The relationship between middle ear pressure and deviated nasal septum. Clinical Otolaryngology \& Allied Sciences. 1993 Aug;18(4):308-10.

10. Jerger J. Clinical experience with impedance audiometry. Archives of otolaryngology. $\quad 1970 \quad$ Oct 1;92(4):311-24.

11. Bluestone CD, Cantekin EI, Beery QC. Certain effects of adenoidectomy on eustachian tube ventilatory function. The Laryngoscope. 1975 Jan;85(1):11327.

12. Uzun C, Adali MK, Tas A, Koten M, Karasalihoglu AR, Devren M. Use of the nine-step inflation/deflation test as a predictor of middle ear barotrauma in sports scuba divers. British journal of audiology. 2000 Jun 1;34(3):15363.

13. Swarts JD, Alper CM, Mandel EM, Villardo R, Doyle WJ. Eustachian tube function in adults without middle ear disease. Annals of Otology, Rhinology \& Laryngology. 2011 Apr;120(4):2205.

14. Salvinelli F, Casale M, Greco F, D'ascanio L, Petitti T, Di Peco V. Nasal surgery and eustachian tube function: effects on middle ear ventilation.

Clinical Otolaryngology. 2005 Oct;30(5):409-13.
15. Farneti G, Denaro E. Rhinopharingeal disease and tubal disease. Relations and influences. Middle Ear Disease and Surgery. 1992:199-204.

16. Hone SW, Moodley S, Donnelly MJ, Fenton JE, Gormley PK, Walsh M. The effect of tonsillectomy on eustachian tube function. Clinical Otolaryngology \& Allied Sciences. 1997 Dec;22(6):511-4.

17. Teixeira FM, Tomita S, Lima MA. Evaluation of tympanometric alterations in patients subject to general anesthesia with nitrous oxide. Revista Brasileira de Otorrinolaringologia. 2005 Jun;71(3):274-80..

18. Eyigör H, Osma U, Y1lmaz MD, Aygener N, Buyruk A. The effect of operation success on middle ear ventilation in patients with nasal septal deviation. Kulak burun bogaz ihtisas dergisi: $\mathrm{KBB}=$ Journal of ear, nose, and throat. 2013;23(1):2631.

19. Buchman CA, Doyle WJ, Swarts JD, Bluestone CD. Effects of nasal obstruction on Eustachian tube function and middle ear pressure. Acta Otolaryngol 1999; 119(3): 351-355.

20. Low W K , Williatt D J. The relation between middle ear pressure and deviated nasal septum. Clin Otolaryngol Allied Sci 1993; 18: 308-310.

21. Nudrat Parvez Kamal , Vinek Harkake. Nasal obstruction and Eustachian tube dysfunction: How are they related? Int $\mathrm{J}$ Clin and Biomed Res. 2015;1(3): 46-50.

22. Awad O G A, Salama Y M, ElBadry M. Effect of nasal obstruction surgery on middle ear ventilation. EGO, 2014 (30); 3: 191195. ventilation. EGO, 2014 (30); 3: 191-195.

23. Maier W, Krebs A. Is surgery of the inner nose indicated before 
tympanoplasty? Effects of nasal obstruction and reconstruction on the eustachian tube. Laryngorhinootologie 1998; 77(12): 682-8.

24. Şahin M I, Güleç S, Perişan U, Külahlı I. Does Septoplasty Affect Middle Ear Pressure and Eustachian Tube Function? Erciyes Med J 2014 36(3): 115-8.

25. Yildirim A, Yasar M, Bebek AI. Nasal septal suture technique versus nasal packing after septoplasty. Am J Rhinol 2005;19:599-602.

26. Thompson AC, Crowther JA. Effect of nasal packing on Eustachian tube function. J Laryngol Otol 1991;105:539-540.

27. Deron P, Clement P A, Derde M P. Septal surgery and tubal function: early and late results. Rhinology $1995 ; 33: 7-9$ 